\title{
The limits of background justice
}

\author{
Thomas Porter \\ Forthcoming in Social Philosophy \& Policy volume 30, issues 1-2 \\ (C) Cambridge University Press
}

\begin{abstract}
The argument from background justice is that conformity to Lockean principles of justice in agreements and transactions does not preclude the development of inequalities that undermine the freedom and fairness of those very transactions, and that, therefore, special principles are needed to regulate society's "basic structure". Rawls offers this argument as his "first kind of reason" for taking the basic structure to be the primary subject of justice.

Here I explore the background justice argument and its implications for questions about the scope of distributive justice. Recent contributions to the literature on global justice have drawn on the background justice argument in order to answer these questions. Yet there has been no systematic analysis of the argument or its implications. I offer that here.

As it turns out, the background justice argument can offer no independent support for conclusions about the scope of distributive justice. For the special principles that it justifies inherit their scope from conclusions that must be established or assumed in advance. These prior conclusions are precisely what is at issue in debates about global justice.
\end{abstract}

\section{$\underline{\text { Introduction }}$}

Rawls says that the primary subject of justice is what he calls the "basic structure" of society. The basic structure is, roughly speaking, the way in which major social institutions fit together and distribute or regulate the distribution of important benefits and burdens. What it means to say that this is the primary subject of justice is that principles designed to regulate it have "a certain regulative primacy", and that such principles are an appropriate primary focus for a theory of justice, as they are for Rawls. 
Rawls gives more than one reason to explain why the basic structure should be the primary subject of justice. Here, I want to discuss one that we can call "the argument from background justice", which he presents as a critique of Lockean "ideal social process" views, such as the one advanced by Nozick in Anarchy, State, and Utopia. ${ }^{2}$ The general idea is that reflection on the long-term effects of transactions between individuals that seem unobjectionable in themselves reveals a need for principles of distributive justice that are standards of assessment for institutions, and not only for the transactions themselves, that must be satisfied if those transactions are really to be unobjectionable. Rawls appeals, in particular, to objectionable inequalities in property and opportunities that are not precluded by attractive standards of justice for individual transactions. But the key point is not merely that such inequalities are unjust, and that, therefore, Lockean views that disregard it are unsatisfactory. The point is that unequal background conditions undermine the freedom or fairness of the Lockean principle-respecting transactions themselves.

My ultimate aim in this paper is to uncover the background justice argument's implications for the contemporary debate about global justice. But, as we'll see, there is more than one way to understand the argument and its target, and the force and source of its conclusions vary with the interpretation. So, much of the paper will be given over to anatomizing the possibilities of the background justice argument, attempting to determine under what conditions it might have force against Lockeans. This work will put us in a position to see more clearly, at the end of the paper, the argument's bearing on the debate about global justice.

Why would you think that it would have any bearing? As anyone familiar with the debate will know, questions about the bearing of Rawlsian ideas in particular on issues of global justice loom large in it. One avenue of interest involves attempting to infer from Rawls's own reasons for making the basic 
structure the primary subject of justice to conclusions about the scope of the principles that he advocates, by which I mean the set of people by reference to the distribution of benefits and burdens among whom those principles set a standard. So, for example, one might suppose that his appeal to the "profound and pervasive influence ${ }^{\prime \prime}$ of the institutions of the basic structure gives us reason to suppose that the logic of the Rawlsian position supports a conception of Rawlsian distributive principles as including in their scope all those who are profoundly and pervasively influenced by the institutions. ${ }^{4}$ By taking the basic structure of a closed society to be the primary subject of justice, Rawls himself effectively makes the scope of the principles the set of people whose cooperation together is governed by that basic structure-which excludes some of those who are profoundly and pervasively influenced by it. And in the Law of Peoples he advances a theory of global justice that reaffirms that restricted conception of the principles' scope. ${ }^{5}$ But-so goes the thought-his reasons for taking the basic structure to be primary may turn out to support a conception of the principles' scope that is at odds with his own conclusions about it.

Now, since the background justice argument is presented as a reason for thinking that the basic structure should be subject to special distributive principles, it looks as if it, too, might be recruited in this way in the debate about global justice. And, indeed, two recent contributions to the debate, by Arash Abizadeh and Miriam Ronzoni, have drawn on it. ${ }^{6}$ However, although they appeal to the same argument, Abizadeh and Ronzoni derive from it opposing conclusions about the scope of distributive justice. So, although the background justice argument looks promising for those seeking to establish conclusions about scope, it remains unclear precisely which conclusions it supports, if any.

I shall argue that-in spite of its promise-the background justice argument, on any plausible interpretation, doesn't by itself imply anything about 
the scope of distributive justice. For the special principles that it justifies inherit their scope from the scope of the principles for the transactions that it identifies as problematic, or else from the scope of the ideals that form the basis of its critique of the distributions that conformity to those latter principles doesn't preclude. The appropriate scope of those latter principles and ideals, however, is no clearer or less controversial than the appropriate scope of the special distributive principles. Thus, the background justice argument can offer independent support neither to those who take a "cosmopolitan" view of the special distributive principles nor to their opponents. It simply reproduces conclusions that its proponents take to have been established already. My conclusion, then, is that the background justice argument is neutral with respect to the global justice debate.

I proceed as follows. In section 1 below, I elaborate a little more on what it means to say that the basic structure is the primary subject of justice, so as to clarify the relation between Rawls's claim that the basic structure is the primary subject of justice and the distributive principles whose scope is the focus of debates about global justice and which the background justice argument purports to justify. Then, in section 2, I set out Rawls's presentation of the argument itself in Political Liberalism and Justice as Fairness: A Restatement. I go on, in sections 3 and 4, to analyze two different possible interpretations of the argument and its force: first, as an internal critique of the Lockean view as an objection to which Rawls presents it; second, as an external critique of that view. My aim in these two sections is to set out and analyze all of the various forms (both more and less true to Rawls's own intentions) in which one might plausibly try to press the background justice argument, so that when I come to assess its implications for questions of global justice-as I do in section 5-my conclusion is made secure by the comprehensiveness of the analysis. Because I am interested in the implications of plausible forms of the background justice argument, I shall inevitably be engaged in 
some assessment of the argument in its various forms. But neither definitive assessment nor attribution of any particular form of the argument to Rawls is my aim.

\section{1. "The basic structure as subject"}

The basic structure is "the way in which the major social institutions fit together into one system, and how they assign fundamental rights and duties and shape the division of advantages that arises through social cooperation." ${ }_{s}$ This definition makes use of the notion of a social institution, which is, Rawls says,

a public system of rules which defines offices and positions with their rights and duties, powers and immunities, and the like. These rules specify certain forms of action as permissible, others as forbidden; and they provide for certain penalties and defenses, and so on, when violations occur. As examples of institutions, or more generally social practices, we may think of games and rituals, trials and parliaments, markets and systems of property.

Thus, according to these definitions, we have a social institution when we have a pattern of behavior that can plausibly be regarded as a pattern of shared rulefollowing. There is some set of rules, that is, that are generally recognized and intentionally followed as a single, shared set of rules among a given population. And we have the institutions of a basic structure when there is a set of major social institutions that can be regarded as fitting together into one system and assigning fundamental rights and duties and shaping the division of advantages that arises 
through social cooperation. As examples of such major social institutions, Rawls names "[t]he political constitution with an independent judiciary, the legally recognized forms of property, and the structure of the economy... as well as the family in some form". ${ }^{10}$

What does it mean to say that the basic structure is the primary subject of justice? One thing that it means is that the principles of justice for the basic structure-i.e. principles governing the way in which the major social institutions fit together, assign rights and duties, and distribute advantages—-have "a certain regulative primacy with respect to principles and standards appropriate to other cases." "In other words, principles of justice for the basic structure have priority over principles of justice for other things (including any principles of justice for individuals that themselves define social institutions). And, since justice is the "first virtue" of social institutions, ${ }^{12}$ principles of justice for the basic structure presumably have priority over other types of principle for the basic structure as well.

This "priority claim" could be understood in either of two ways. It could be taken to assert priority in content, according to which the content of principles for subjects other than the basic structure (or other types of principles for the basic structure) is constrained by the requirement of compatibility with the principles of justice for the basic structure, which are not themselves constrained by any analogous requirement. So, to say that principles for the basic structure have priority in content over principles for other things, or other types of principles for the basic structure, would be to say that if there were a conflict between the requirements of the former and those of the latter, the latter principles ought to be rejected as unsound, rather than their requirements merely overridden. Alternatively, the priority claim could be taken to assert priority in conflict, according to which the content of principles for subjects other than the basic 
structure (or other types of principles for the basic structure) is not constrained by any such requirement, but satisfaction of the prioritized principles has priority over satisfaction of other principles. ${ }^{13}$ Priority in conflict thus understood is like the priority that principles of morality are often thought to have over principles of self-interest, for example.

However we understand the priority claim, it should be clear that any argument that supports the view that the basic structure is the primary subject of justice supports a far-reaching conclusion, viz., that special principles regulating the way that the basic structure distributes advantages and disadvantages have priority even over the principles conformity to which produces the relevant distributions, so that such principles are to be outweighed or modified if their operation results in violations of the special principles. Thus, we see, special principles for the basic structure constitute a weighty class of principle. So, conclusions about their scope are important conclusions..$^{14}$

\section{The argument from background justice}

Now let us turn to the background justice argument itself, which purports to justify these weighty special principles. It will help to begin with its conclusion, which is that a "division of labor" is needed

between two kinds of principles, each kind suitably specified: first, those that regulate the basic structure over time and are designed to preserve background justice from one generation to the next [call these background principles-TP]; and second, those that apply directly to the separate and free transactions between individuals and associations [call these foreground 
principles-TP]. Defects in either kind of principle can result in a serious failure of the conception of justice as a whole. ${ }^{15}$

Foreground principles, then, are standards of assessment for the interactions between individuals and associations-they pick out, say, assaults and fraudulent transactions as unjust. Foreground principles will typically be enshrined in the institutions of the basic structure, in legal rules prohibiting assault and fraud, for example. Background principles, meanwhile, are standards of assessment for the way in which benefits and burdens are distributed, among those to whom the rules of the institutions of the basic structure apply, as a result of their shared rulefollowing. They pick out certain ways in which the institutions produce distributions as unjust. One way of doing this is by reference to the distributions themselves; that's how Rawls's difference principle works. So, background principles don't tell us directly about the justice and injustice of transactions between individuals and associations, but they do tell us about the justice and injustice of the way in which the institutions that regulate those transactions combine with other major institutions to produce distributions of benefits and burdens. And one of the ways in which they can do that is by reference to the distributions themselves.

Since some views take there to be no need for background principles, concentrating only on foreground principles, Rawls regards the argument for the division of labor between background and foreground principles as an "important criticism" of such views. ${ }^{16}$ In particular, he identifies Locke and Locke's inheritor Nozick as targets of the criticism. He characterizes the reasoning that underpins their positions as follows:

Suppose we begin...with the attractive idea that persons' social 
circumstances and their relations with one another should develop over time in accordance with free agreements fairly arrived at...we might use certain [foreground] principles to specify various rights and duties of persons, as well as their rights to acquire and transfer property. Now suppose we start with a just initial state in which everyone's possessions are justly held. We then say that when everyone respects persons' rights and duties, as well as the principles for acquiring and transferring property, the succeeding states are also just, no matter how distant in time. ${ }^{17}$

The important criticism of this reasoning is as follows:

Even though the initial state may have been just, and subsequent social conditions may also have been just for some time, the accumulated results of many separate and seemingly fair agreements entered into by individuals and associations are likely over an extended period to undermine the background conditions required for free and fair

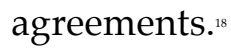

One way in which Rawls tells us that background conditions may be eroded is that "[v]ery considerable wealth and property may accumulate in a few hands, and these concentrations are likely to undermine fair equality of opportunity, the fair value of the political liberties, and so on." ${ }_{19}$ What is required to prevent this erosion-to maintain "background justice" — is that "excess market power must be prevented and fair bargaining power should obtain between employers and employees",,$^{20}$ and that "existing wealth must have been properly acquired and all must have had fair opportunities to earn income, to learn wanted skills, and so on." ${ }^{21}$ In short: background justice calls for limits on inequality of property and 
opportunities. But inequality that exceeds these limits is not precluded by even perfect conformity to the foreground principles with which we began. So, the foreground principles turn out to be inadequate.

It's important to see that Rawls is not merely suggesting that inequality is unjust, and that therefore Lockean views that disregard it are unsatisfactory. That is an argument that many-including Rawls—might make, but it would not be the background justice argument, as I understand it. The point of the background justice argument is that unequal background conditions undermine the freedom or fairness of the Lockean principle-respecting transactions themselves, and not merely that unequal background conditions are objectionable anyway. The problem, then, is to find a way of facilitating the continued expression over time of the values that the Lockean foreground principles were originally designed to express.

This problem cannot be solved, Rawls goes on to argue, by supplementing the original foreground principles with further foreground principles that are designed to prevent the erosion of background justice. For "the rules governing agreements and individual transactions cannot be too complex, or require too much information to be correctly applied...[or] impose excessive transaction costs", if they are not to "exceed the capacity of individuals to grasp and follow them with sufficient ease, [and] burden citizens with requirements of knowledge and foresight that they cannot normally meet"..2 And the information, foresight, deliberation, and coordination that foreground principles aimed at preserving background justice would require would violate these conditions. Principles for the basic structure need not be subject to such demanding conditions, since institutional agents can deal with much more information and complexity. ${ }^{33}$ Hence, it is only through institutional conformity to the requirements of specially designed principles for the basic structure that background justice-and, hence, justice simpliciter-can be preserved. Thus, as Rawls says, we are led to the idea 
of an institutional division of labor between background principles for the basic structure and foreground principles for individuals.

If it's successful, the background justice argument looks as if it will provide a good explanation of the priority claim. For Rawls says that "[t]hat...rules of background justice are in force over time does not detract from but rather makes possible the important values expressed by free and fair agreements reached by individuals and associations within the basic structure." ${ }_{24}$ Unless background principles have priority over the foreground principles, then their capacity to enable the expression of these values through conformity to the foreground principles won't be secure. For it won't be guaranteed that conformity to the foreground principles won't conflict with and outweigh conformity to the background principles.

It follows that principles of background and principles of foreground justice are not symmetrically situated. Whereas the priority of foreground over background principles would risk undermining the important values expressed by transactions that conform to the former, it's not the case that the priority of background over foreground principles risks undermining those same values. For seemingly free and fair agreements are really free and fair agreements, according to the background justice argument, only insofar as they are reached under the conditions that satisfy the background principles in the first place.

3. The argument as an internal critique of Lockean views

It's possible to draw from Rawls's discussions of the background justice argument both an internal and an external critique of the Lockean views to which it constitutes an objection. ${ }^{25}$ In this section, I'll analyze the internal critique, which is 
that the Lockean fails to live up to her own commitments to freedom and fairness, commitments that she takes to be adequately expressed in the exclusively foreground principles that characterize her views. According to the background justice argument thus interpreted, perfect conformity to these principles is compatible with the emergence of certain inequalities between individuals whose interactions will not, just in virtue of those inequalities, be free and fair in the very sense that the Lockean cares about. The inequalities undermine the point of conformity to the requirements of the foreground principles. Moreover, the inequalities cannot be precluded by conformity to any feasible foreground principles. So, the just background that is provided by special, prioritized regulation of the basic structure is needed alongside the just foreground that conformity to the requirements of the Lockean foreground principles secures only when that background is in place.

Under what conditions has this critique any force? (Answering this question is a necessary precursor to analyzing the implications of the background justice argument for debates about global justice, since a critique with no force presumably has no interesting implications of its own for those debates.) The critique depends upon the attribution to the Lockean of commitments to freedom and fairness in agreements that are not compatible with a (relevantly) unequal background distribution. Yet Lockeans typically deny that the freedom of a transaction-at least insofar as this makes a difference to its justice-is undermined by inequality between the parties to it-even when one of them has no alternative to the transaction that we would regard as acceptable to her. ${ }^{26}$ So, insofar as the internal critique depends upon the attribution to the Lockean of a commitment to freedom that renders a transaction between sufficiently unequally placed parties unfree, it seems destined to fail.

One possible response here is to argue that insofar as Lockeans are working 
with an everyday intuitive conception of freedom in transactions, they must accept that even perfect conformity to Lockean foreground principles can't preclude the possibility of transactions into which some parties are effectively forced, and which are therefore unfree. ${ }^{27}$ So, their commitment to freedom in transactions can be upheld only insofar as the view is supplemented with background principles that guarantee that no one will be effectively forced by the inadequacy of available alternatives into any transaction. However, contemporary Lockeans, at least, are likely to reply that their initially attractive idea is that of self-ownership, or that their favored interpretation of the ordinary concept of freedom is well expressed by the idea of self-ownership, and that their view is that persons' social circumstances and their relations with one another should develop over time in accordance with interactions that respect rights expressive of that attractive idea. It is implausible to interpret this as an ideal of freedom that commits them unwittingly to the primacy of the basic structure. A critique that appeals, then, to a background justice-necessitating conception of freedom will be an external critique, one that starts from commitments that Lockeans are not presumed to share, not an internal one. (I'll consider it in section 4 below.)

Could one appeal to a Lockean commitment to fairness, rather than freedom, as the basis for the internal critique? Lockeans typically deny that the fairness of an agreement can be undermined by inequalities in holdings, as opposed to by the violation of foreground principles prohibiting fraud, for example. That would suggest that a Lockean commitment to fairness in agreements cannot be appealed to as a way to generate the internal critique. However, considerations relating to the justice of initial acquisitions might offer a way for proponents of that critique to gain a foothold. For Lockeans do typically accept that the justice of a distribution of property is undermined insofar as the relevant parties' positions arise as a result of unjust initial acquisitions, even if no 
further foreground principle-violating transactions take place afterwards. And it is plausible to understand the injustice of unjust initial acquisitions-acquisitions that violate a Lockean proviso, under some favored interpretation-in terms of an ideal of fairness.

This may take us far from Rawls's own intentions, ${ }^{28}$ but it is worth investigating for the sake of comprehensiveness in assessing the possibilities for the background justice argument. So, let us distinguish three different Lockean positions. First, there are those who reject any proviso. According to these Lockeans, there are no constraints on the acquisition of unowned resources: one may justly acquire as much as one is able by means of the appropriate procedure (e.g. labor-mixing) of what is unowned, no matter how that affects the others against whom one gains new rights as a result. We can call these Lockeans "hard libertarians". Next, there are those who accept a non-egalitarian proviso, that is, a proviso that seems to have no substantially egalitarian implications, but nevertheless restricts the value or extent of unowned resources that may be initially acquired without compensation for those who gain new duties to the owner as a result of the acquisition. Call these Lockeans "soft libertarians". Nozick, who endorses a proviso on initial acquisitions according to which justice forbids any acquisition as a result of which those other than the acquirer are (through, we can add, no choice of their own) worse off, and uncompensated for that, than they would have been in a state of nature, is a soft libertarian. ${ }^{2}$ Finally, there are those who accept an egalitarian proviso, whom we can call "left libertarians" ${ }^{30}$

Whether the background justice argument has any force as an internal critique depends upon which of these three positions it is directed against. Clearly, it fails altogether insofar as it is directed against hard libertarians. For they do not regard the justice of transactions as undermined by any background distribution of 
holdings or opportunities that is the result of conformity to Lockean foreground principles, among which no proviso on initial acquisition is, by hypothesis, included. (Henceforth, when I talk about background distributions of holdings and opportunities, I'll be assuming that they come about without violation of any Lockean foreground principles, excluding provisos on initial acquisition.) Thus, any version of the background justice argument that is intended to have force against hard libertarians must be an external critique.

Soft libertarians do not think that the fairness of transactions is undermined by an unequal background distribution of holdings or opportunities as such, but only by a background distribution that arises as a result of initial acquisitions and leaves relevant parties below the level specified by the proviso. The lowest level that a soft libertarian proviso is likely to specify is the one identified by Nozick and described above. Now, it's implausible to regard this level as inevitably surpassed in a world in which the gains made possible by private property and the free market under conformity to exclusively foreground exchange-governing principles are achieved. (Nozick does not so regard it.) ${ }^{31}$ Much depends, of course, upon our characterization of the pre-property "state of nature" and how it would have developed,,$^{32}$ upon what counts as arising as a result of initial acquisition, and upon our account of the bearers of the liabilities to ensure that relevant parties do not fall below the relevant level. But it need be no part of the soft libertarian's characterization that life in the state of nature is unbearable, or that liabilities to ensure the proviso's satisfaction rest only with the initial acquirer, rather than travelling with the resources acquired, for example.

Since it is surely beyond the capacities of individuals by themselves to follow rules requiring that initial acquisitions conform to the proviso in any moderately large or complex society, or to track the bearers of the liabilities that the proviso generates, it seems that a fairly low-threshold sufficientarian analogue 
of the background justice argument will succeed against some soft libertarians, at least for the duration of the lives of contemporaries of initial acquisitions. More precisely, a "luck sufficientarian" background justice argument will be applicable, according to which there is a need for background principles designed to ensure that individuals fare as well as the soft libertarian proviso says that they must.

Whether this background justice argument can justify background principles that apply in the period after that, though, depends upon whether the soft libertarians whose views it addresses take their favored proviso to refer not only to the situations of those who are alive at the time of initial acquisitions, but also to those of people who come into being later on. If they don't, then, at some point, once all unowned resources have been appropriated, so that there can be no further initial acquisitions, then the need for background principles to ensure the proviso's satisfaction will come to an end, on these soft libertarians' views. If they do, then the background justice argument can justify background principles and the consequent primacy of the basic structure in perpetuity.

There are complex philosophical questions of intergenerational justice here, as well as historical questions about who originally acquired what, and when. Rather than attempt to work these out, I simply note that the force of the background justice argument depends (in ideal theory), ${ }_{, 3}^{33}$ on the answers that soft libertarians give (which will depend, at least in part, on their reasons for thinking that the institution of private property in external resources need not be incompatible with fairly extensive inequalities). It has most force, although not, of course, egalitarian force, against those soft libertarians who take the justice of people's property holdings at any point to be conditional on no one's doing worse than the soft libertarian proviso specifies-no matter whether she was around at the time of any initial acquisitions or not. It has the most force against such soft libertarians because it justifies luck sufficientarian background principles and the 
primacy of the basic structure, not only for the duration of the lives of contemporaries of initial acquisitions, but in perpetuity.

Like soft libertarians, left libertarians do not regard the fairness of transactions as undermined by an unequal background distribution of holdings or opportunities as such, but only by a background distribution that arises as a result of initial acquisitions and leaves relevant parties below the level specified by the proviso. What distinguishes left libertarians is their commitment to a substantively egalitarian proviso, such as one that disallows initial acquisitions that leave others without equal access to an equal share of initially unowned resources. ${ }^{34}$ So, by much the same reasoning that led us to a luck sufficientarian analogue of the background justice argument against the soft libertarian, we can arrive at something closer to Rawls's own egalitarian background justice argument against the left libertarian, according to which there is a special role for the basic structure on account of the need for background principles designed to ensure that individuals fare as well as the egalitarian proviso says that they must.

As with the argument against the soft libertarian, whether this argument justifies background principles in perpetuity or only for the duration of the lives of contemporaries of initial acquisitions depends upon whether left libertarians take their favored proviso to refer not only to those who are alive at the time of initial acquisitions, but also to those who come into being later on. As before, there are complex matters to consider here, and, as before, I simply note that the force of the background justice argument against left libertarians (in ideal theory) depends on how they deal with these issues. It has most force against those left libertarians who take the justice of people's property holdings at any point to be conditional on no one's ever having less than an egalitarian share of the resources that were once unowned-no matter whether she was around at the time of any initial acquisitions or not. It has the most force against such left libertarians because it 
justifies background principles and the primacy of the basic structure, not only for the duration of the lives of contemporaries of initial acquisitions, but in perpetuity.

The background justice argument seems compelling, then, as an internal critique of left and some soft libertarians. But the possibility of hard libertarianism as well as a restricted conception of the duration of the proviso's applicability limits its force as a critique of Lockeans in general..$^{35}$

\section{The argument as an external critique of Lockean views}

Whereas the internal critique accuses the Lockean of failing to live up to her own commitments to freedom and fairness, the external critique is that those commitments need supplementing or replacing with different commitments if the Lockean foreground principles are to facilitate genuine freedom and fairness in transactions as the relations between people develop over time. According to the critique, this is because even perfect conformity to the foreground principles is compatible with the emergence of inequalities between individuals, whose conforming interactions will fail, just in virtue of those inequalities, to be genuinely free and fair. Ensuring that those inequalities don't emerge is beyond the capacity of individual rule-followers. So, the just background that is provided by special regulation of the basic structure is needed alongside the just foreground that conformity to the requirements of the Lockean foreground principles secures only when that background is in place.

This argument's plausibility depends primarily upon the plausibility of the claims about what is necessary for the foreground principle-respecting transactions under scrutiny to be genuinely free and fair-claims to which, by hypothesis, the Lockeans in question are not automatically committed. What is 
probably the most intuitively plausible (and familiar) version of the argument focuses on threats to the freedom of the transactions, building on the thought that parties do not really enter into the transactions freely insofar as their alternative options are insufficiently attractive. This is the external critique that I mentioned in section 3, which takes issue with the idea that the ideal of self-ownership is an adequate interpretation of the ideal of freedom. To see how it would go, consider the following conditions, proposed as constitutive of an intuitive and fairly stringent conception of transactional freedom: ${ }^{36}$

(a) The parties to the transaction act in accordance with principles ruling out fraud and deception

(b) No party is forced or coerced to accept the terms offered by any other

(c) No party's position is the result of any prior violation of (a) or (b) $)^{37}$

The first condition and the coercion component of the second condition are uncontroversially met by conformity to the requirements of Lockean foreground principles. The external critique that we are considering would be based on the idea that the force component of the second condition, by contrast, is not necessarily met by such conformity. For, in spite of such conformity, distributions may develop in which some individuals are effectively left with no adequate alternative to accepting unfavorable terms. In this way, the background justice argument claims, Lockean foreground principles do not preclude transactions into which some parties are effectively forced, and which are in that sense unfree. Given that no foreground principles that individuals could feasibly follow by themselves can rectify the problem, background principles are needed. 
These background principles need not be particularly egalitarian. They need only protect people from being forced to accept unfavorable terms, and it is not the case that one is effectively forced into any transaction that one enters into from an initial position that is not equal to that of the other parties to the transaction. One may avoid being forced into transactions so long as one has enough to be in a position to turn them down, and that, surely, may be much less than as much as others. So, a distribution that satisfies sufficientarian background principles-principles that require that each person have enough-may be necessary to avoid effective forcing, ${ }^{\text {, }}$ but an egalitarian distribution is not.

A different version of the external critique-compatible with the firstwould focus on threats to the fairness of transactions that are not dispelled by conformity to Lockean foreground principles. One option is to run a left or soft libertarian argument about fairness in initial acquisition against hard libertarians, but, since we've already discussed the way in which this would generate a need for background justice, I'll say no more about it here. Alternatively, one might argue that-regardless of any provisos_inequalities of opportunity and certain inequalities of bargaining power render the relevant transactions unfair, even if they are not unfree in the sense just described. (In order to avoid the suspicion that the judgment of the unfairness of the inequalities in question is ultimately based only on the supposition that they make the transactions unfree, we can imagine an unequal distribution of opportunities and property that nevertheless satisfies the sufficientarian background principles envisaged above, as well as the condition that no Lockean foreground principles have been violated in its genesis.) $)^{39}$

What would ground the claim that the imagined inequalities were unfair? In the Rawlsian view, the natural place to look is at Rawls's reasoning from the ideal of society as a fair system of cooperation between citizens regarded as free 
and equal and the original position that models that ideal, or at the idea of fair reciprocity that he thinks is appropriate for such a system. I take it that these lines of reasoning are familiar enough for there to be no need to say any more about them here. Other views might appeal to the intrinsic unfairness of inequality, or something else again (which need not be specifically egalitarian).40 What should be clear, in any case, is that the force of this version of the external critique depends upon the detail of such arguments. Whereas the ordinary conception of freedom in transactions that motivates the first version of the external critique has a great deal of intuitive plausibility by itself, it isn't clear that any everyday intuitive conception of fairness in transactions will explain what is wrong with transactions between unequally situated parties, especially in a society that is regulated by freedom-securing background principles. Indeed, an everyday conception of fairness in transactions looks to be reasonably well expressed by the Lockean foreground principles (a) and (b) listed above. Rather, the claim of unfairness, and so the external critique of Lockean views, must be grounded in broader, patterned distribution-implying social ideals of fairness. The critique would be that the seeming fairness of foreground principle-respecting transactions is hollow when the relevant social ideal goes unrealized. And, since it would not be feasible for individuals to follow rules designed to realize the social ideal, background principles are needed. But whether the appropriate background principles are egalitarian, sufficientarian, or something else will depend upon the nature of the broader social ideals in question.

So, the background justice argument, understood as an external critique of the Lockean views in question, has force as a justification of sufficientarian background principles and the primacy of the basic structure to the extent that the everyday intuitive conception of freedom in transactions or a sufficientarian distributive pattern-implying social ideal is independently compelling. 
Meanwhile, it has force as a justification of distributively more demanding background principles-such as the difference principle or the principle of fair equality of opportunity - and the primacy of the basic structure only to the extent that a more demanding distributive pattern-implying social ideal of fairness is compelling."

\section{The scope of principles of background justice}

I have not attempted to investigate or assess the details of the arguments for the social ideals or the intuitive conception of transactional freedom that might provide the basis of the external critique, or those of the arguments for one version of libertarianism as against the others. For my purposes-the purposes of determining the implications of the background justice argument-there is no need to do this, because we are already in a position to see that neither the external nor the internal critique can be an original source of any implications about scope, even if it is successful.

As we saw, the scope of a principle of background justice is the set of people by reference to the distribution of benefits and burdens among whom the principle sets a standard. If that set includes all or nearly all existing people, we can say that the scope is cosmopolitan. If the set includes all and only those who are denizens of the same state, it is statist. Of course, there are intermediate positions too, ${ }^{42}$ but distinguishing only these two will serve my purposes.

Since, as we have seen, the background justice argument can be interpreted in a number of ways, and since, furthermore, I am not so interested here in the scholarly question which interpretation to attribute to Rawls, it seems simplest to proceed by considering the implications of each of the interpretations in turn. 
Such comprehensiveness as we thereby achieve will make the conclusion all the more secure.

I begin, then, with the internal critique. As we saw, insofar as the background justice argument has any force as an internal critique, it has it against left and some soft libertarians, and particularly those who take the justice of people's property holdings at any point to be conditional on no one's having less than the stock of property or opportunities specified by the relevant provisowhether she was around at the time of any initial acquisitions or not. According to the background justice argument as applied to these views, once initial acquisitions begin (in any number, at least), the basic structure will be answerable to a standard set by principles of background justice whose role is to ensure that the proviso is not violated. What is the scope of these principles-and, hence, that of the basic structure that is answerable to them? Our analysis suggests that this must be determined by the scope of the proviso: those who fall within the scope of the background principles must be those whose holdings or opportunities determine whether the proviso has been satisfied. For it is only the proviso's requirements that can generate the internal critique. So, the scope of the background principles is effectively inherited from the proviso.

It follows that whether the background justice argument qua internal critique justifies background principles with cosmopolitan scope or not will be a matter of the cosmopolitanism or otherwise of the Lockean view against which it is directed. Because Lockeans are typically natural rights theorists, and natural rights theorists are typically cosmopolitans about the scope of the principles that specify the rights, one would expect the internal critique typically to generate cosmopolitan conclusions regarding the scope of the background principles and the basic structure that it justifies. But, since the proviso and the other Lockean foreground principles appear to stem from divergent normative sources, the 
proviso might in principle have different scope from that of the other foreground principles. Moreover, Lockeans need not be cosmopolitans even about the other foreground principles anyway. A statist explanation of their applicability to the interactions between fellow citizens, combined with an internationalist explanation of the principles applicable to transnational individual interactions, is possible. And if they are not cosmopolitans, then the internal critique is powerless to compel cosmopolitanism about the background principles that it justifies, even if it succeeds. Inversely, even a successful internal critique is powerless to compel statism about the background principles that it justifies if the Lockean view against which it is directed is cosmopolitan. Thus, the implications for questions of global justice of the background justice argument qua internal critique depend upon prior conclusions about scope, and cannot generate or explain them. And, since the arguments for such prior conclusions about the scope of Lockean foreground principles and provisos will be no less controversial than conclusions about the scope of principles of background justice, the background justice argument's inheritance of the former can't settle controversies about the latter.

What about the external critique? As we saw, the background justice argument qua external critique justifies sufficientarian background principles and basic structure primacy to the extent that the everyday intuitive conception of freedom is compelling. And it justifies distributively more demanding background principles and basic structure primacy to the extent that a distributively more demanding social ideal is compelling. ${ }^{43}$ Now, when the argument's justification of sufficientarian background principles focuses on the inadequacy of the Lockean conception of transactional freedom, the background principles in question do seem to inherit the scope of the Lockean standards against which the critique is directed. Although, strictly speaking, it would not be incoherent to claim that that Lockean conception is inadequate as a conception of 
freedom in transactions between, say, fellow citizens, yet perfectly adequate as a conception of freedom in transactions between citizens of different states, it is natural to think that the critique focuses on freedom in any transactions to which the Lockean standards apply, so that it inherits the scope of those standards. Thus, we reach the same conclusion about the implications of the external critique, insofar as it is based on a non-Lockean ideal of transactional freedom, as we reached about the implications of the internal critique: they depend upon prior conclusions about scope, and cannot generate or explain those conclusions.

However, insofar as the external critique is taken to justify background principles by appeal to a distributively demanding social ideal of fairness, things are different. As we saw, the critique justifies background principles to the extent that a distribution-implying social ideal is compelling. Here, what was only really raised as a formal possibility when the external critique was based on non-Lockean ideals of transactional freedom is raised as a real possibility when it is based on a distributively demanding social ideal. For the social ideal in question might apply to the relations between only a subset of those to whose interactions the Lockean takes her favored foreground principles to apply. So, the background principles that are justified by the external critique clearly won't inherit the foreground principles' scope.

By way of illustration, suppose, as many statists do (for reasons not having to do with background justice), that the social ideal that Rawls means to articulate is applicable to the relations between fellow citizens of the same state, but not to the relations between citizens of different states. That social ideal is partly expressed in the egalitarianism of the difference principle, and it could provide the basis of a background justice argument, taking the form of an external critique, against even a cosmopolitan Lockean view. The argument would be that the seeming fairness in transactions realized by conformity to Lockean foreground 
principles is hollow-that such conformity is incapable of realizing the values that it is intended to realize-in the absence of egalitarian background justice, as secured by appropriate regulation of the basic structure. For such conformity is compatible with the emergence of inequalities that undermine fair relations between citizens, as captured in the social ideal. But of course the only inequalities that matter for the purposes of this critique are those that obtain between a subset of those to whom the cosmopolitan Lockean foreground principles apply, namely, those who are fellow citizens. Thus, the scope of the background principles-and, hence, the basic structure-justified by the external critique insofar as it is based on a Rawlsian social ideal depends upon the scope of the social ideal.

So, though the route is different, the destination is the same. In this story, the background justice argument itself once again neither generates nor explains any conclusions about the scope of the background principles that it justifies. Such conclusions are already established (or at least presupposed) by the time we come to bring the relevant social ideal to bear in making the argument. As with the external critique when it is based upon a non-Lockean ideal of transactional freedom, and as with the internal critique in any form, the external critique here simply inherits other arguments' implications for the scope of distributive justice. And, since conclusions about the scope of distributively demanding social ideals are precisely what many of the contributors to the debate about global justice are arguing about, an argument that merely inherits them cannot settle those debates.

\section{Conclusion}

Above, I mentioned recent arguments by Arash Abizadeh and Miriam Ronzoni that appeal to the background justice argument to draw opposing conclusions 
about the scope of specifically Rawlsian distributive justice. The foregoing analysis helps to explain their divergence. Although I haven't the space to offer detailed exposition of their arguments, here is a summary. Abizadeh effectively argues that-in a world of global interaction-the background justice argument justifies Rawlsian distributive principles with cosmopolitan scope." But, as the analysis shows, the background justice argument yields that conclusion only if cosmopolitan scope is already assumed-either for the Lockean view that is the argument's target, or for the distributively demanding social ideal that is the basis of one form of the external critique. Similarly, Ronzoni effectively argues that the background justice argument can justify Rawlsian distributive principles with statist scope. ${ }^{45}$ But the background justice argument yields that conclusion only if statist scope is already assumed. It is their divergent assumptions about scopewhich they do not defend-that explain their divergent conclusions about it; the background justice argument itself does no work in the explanation. Thus, the real work in defending either a cosmopolitan or a statist conclusion remains to be done.

As we have seen, the problem is that the ultimate source of conclusions about scope cannot be the background justice argument in any form. That argument merely reproduces pre-established or presupposed conclusions about scope in the form of background principles that inherit that scope. ${ }^{46}$ If we want conclusions about the scope of distributive justice, we must argue for them in some other way.

\section{Notes}

Previous versions of this essay were presented at a workshop at the Central European University in Budapest, July 2012, and at the New Essays in Moral Philosophy conference in Tucson, January 2013. Many thanks to those present for 
their very helpful questions and suggestions. For detailed comments, I am also particularly grateful to Andrew Lister, Jonathan Quong, Miriam Ronzoni, Andrew Williams, and two anonymous referees.

'John Rawls, Political Liberalism (New York: Columbia University Press, 1993), 257.

2Robert Nozick, Anarchy, State, and Utopia (New York: Basic Books, 1974).

${ }^{3}$ John Rawls, Justice as Fairness: A Restatement, ed. Erin Kelly (Cambridge, MA:

Harvard University Press, 2001), 55.

${ }^{4}$ For discussion of this idea, see Abizadeh, "Cooperation, Pervasive Impact, and Coercion", 341-5.

"See John Rawls, The Law of Peoples (Cambridge, MA: Harvard University Press, 1999).

‘See ibid.; and Miriam Ronzoni, “The Global Order: A Case of Background Injustice? A Practice-Dependent Account", Philosophy \& Public Affairs 37, no. 3 (2009).

Since my interest here in anatomizing the background justice argument and its implications, rather than in scholarly exegesis, I'll make no serious effort to defend any one interpretation as the correct interpretation of Rawls. Still, I hope that my discussion will prove useful to anyone interested in that project.

${ }^{8}$ Rawls, Political Liberalism, 258. Compare Rawls, Justice as Fairness, 10.

- Rawls, A Theory of Justice, revised edition (Cambridge, MA: Harvard University Press, 1999), 47-8.

${ }^{10}$ Rawls, Justice as Fairness, 10. It's worth noting that even a minimal Lockean state will have a basic structure.

"Rawls, Political Liberalism, 257-8.

"2 Rawls, A Theory of Justice, 3. 
${ }^{13}$ There are several different possible versions of priority in conflict, which vary at least according to whether satisfaction of the prioritized principles typically or invariably has priority over satisfaction of other principles, whether it has indefeasible or only prima facie priority, and whether satisfying the deprioritized principles has any value at all in a conflict. I disregard these complications here. ${ }^{14}$ The priority claim is not all that Rawls has in mind when he says that the basic structure is the primary subject of justice. He also means, I believe, to assert what we can call the "focus claim", namely, that the basic structure is that for which an important type of principles of justice, meriting theoretical consideration before of other types of principles, should be designed to constitute standards of assessment (see his comments on "unity by appropriate sequence" at Political Liberalism, 25962. The focus claim would be a natural correlate of priority in content, but not so much of priority in conflict.

${ }^{15}$ Rawls, Justice as Fairness, 53-4.

${ }^{16}$ Ibid., 52.

${ }^{17}$ Ibid., 52-3.

1s Ibid., 53.

${ }^{19}$ Ibid.

${ }^{20}$ Rawls, Political Liberalism, 267.

${ }^{21}$ Ibid., 266.

${ }_{22}$ Ibid., 267, 268.

${ }^{2}$ Compare Samuel Scheffler, "Egalitarian Liberalism as Moral Pluralism", Proceedings of the Aristotelian Society Supplementary Volume 79 (2005).

${ }^{44}$ Ibid.

${ }_{25}$ On the one hand, Rawls might be arguing from the point of view of a commitment to values of freedom and fairness in transactions that we can attribute 
to the Lockean, which suggests an internal critique. On the other hand, the point might be that Lockean freedom and fairness in transactions aren't by themselves genuine freedom and fairness in transactions, which suggests an external critique. My experience of presenting people with these two ways of interpreting Rawls's discussion indicates no decisive majority in favour of one or the other. (My own view is that Rawls intends an external critique.) However that may be, it seems to me that both critiques of Lockean views might coherently be proposed in terms at least very similar to those employed by Rawls. And, since the key conclusion of both critiques is that conformity to the requirements of foreground principles (fully) realizes transactional freedom and fairness only when there is a just background in place, so that special, prioritized regulation of the basic structure is also necessary, both may be regarded as background justice arguments. ${ }^{26}$ See e.g. Nozick, Anarchy, State, and Utopia, 262-4. Nozick suggests that one's entering into a transaction is non-voluntary-and therefore commutative justiceundermining-only if those whose actions place limits on one's alternatives did not have the right to act as they did.

${ }^{27}$ Compare Cohen, Self-Ownership, Freedom, and Equality (Cambridge: Cambridge University Press, 1995), 59-61.

${ }_{28}$ The only thing that Rawls says (Justice as Fairness, 53) about Lockean provisos is that they are insufficiently stringent. He does not consider the possibility of an “egalitarian proviso".

${ }_{29}$ See Nozick, Anarchy, State, and Utopia, 175-8.

${ }^{3}$ See e.g. Michael Otsuka, Libertarianism without Inequality (Oxford: Oxford University Press, 2003); Hillel Steiner, An Essay on Rights (Oxford: Blackwell, 1994); Peter Vallentyne, "Left-Libertarianism: A Primer", in Left Libertarianism and its 
Critics: The Contemporary Debate, ed. Hillel Steiner and Peter Vallentyne

(Basingstoke: Palgrave, 2000).

See Nozick, Anarchy, State, and Utopia, 179-82.

${ }^{32}$ One possibility is that tragedies of the commons would depress material well being even if no one violated Lockean foreground principles. See David Schmidtz, "Taking Responsibility", in David Schmidtz and Robert E. Goodin, Individual Responsibility: For and Against (Cambridge: Cambridge University Press, 1998.) ${ }^{3}$ In non-ideal theory, the waters are muddied even further by the many injustices in initial acquisition and subsequent interactions that we can confidently suppose to have taken place-injustices whose rectification may also call for background principles for reasons similar to those that feature in the background justice argument. (Compare Nozick's suggestion that the difference principle might serve as a rule of thumb for the rectification of historical injustices at Anarchy, State, and Utopia, 231.)

${ }^{34}$ See e.g. Michael Otsuka's description of the egalitarian proviso at Libertarianism without Inequality, 24-5.

${ }^{35}$ What version of the priority claim would a successful internal critique support? The basic idea of the background justice argument, recall, is that background principles make possible the important values expressed by free and fair agreements reached by individuals and associations. How would proviso-dictated background principles do this? The idea must be that unless the relevant proviso's requirements are satisfied, the value of satisfying those of the foreground principles is not fully realized. Since proviso-governed acquisitions of initially unowned resources predate transactions involving those resources, it is plausible enough, within a Lockean ideal historical process framework, to take this view. (I disregard complications arising from the possibility of transactions involving 
resources that are not initially unowned, such as a person's hair [see Otsuka, Libertarianism without Inequality, 18-9].) For that framework makes the justice of holdings at a given time subordinate to the justice of prior transactions and acquisitions, in the sense that one cannot justly own something that rectification of a prior injustice would assign to someone else. (To illustrate: an exchange of stolen goods that conforms in itself to Lockean foreground principles governing exchanges at best realizes only a kind of imitation justice in transactions.) But the interpretation of the priority claim that this seems best to support is priority in conflict rather than priority in content: Lockean foreground principles and proviso-dictated background principles are not obviously expressive of the very same values. (For skepticism about the coherence of proviso-dictating values and self-ownership rights-dictating values in left libertarianism, see Matthias Risse, "Does left-libertarianism have coherent foundations?", Politics, Philosophy, $\mathcal{E}$ Economics 3, no. 3 [2004].) It is true that the values that foreground principles are meant to express, on this picture, are not (or not fully) expressed except insofar as the values expressed by the proviso-dictated background principles are realized. But this is not because the background principles are conceptually prior to the foreground principles. It is simply because of the timing of their demands.

"Compare Ronzoni, “The Global Order,” 239.

${ }^{37}$ See Steiner, An Essay on Rights, 178-87.

${ }^{38}$ Compare Otsuka's description of what he calls "robust self-ownership" at Libertarianism without inequality, 32.

${ }^{39}$ Note that it might be that the proposed case for sufficientarian background principles is overdetermined, because both freedom and fairness in transactions independently call for them. 
*0 Some appeals to such ideals may not support a background justice argument, properly so called, for reasons explained in section 2 above. For the idea that inequality is intrinsically bad because unfair, see Larry Temkin, "Inequality: A Complex, Individualistic, and Comparative Notion", Philosophical Issues 11 (2001).

${ }^{4}$ Which version of the priority claim will the external critique explain if it is successful? The idea is that foreground principles expressing Lockean ideals are inadequately expressive by themselves of genuine freedom and fairness in transactions, despite the appearance of freedom and fairness that conformity to them may generate. But that is not because of the historical priority of background principles (as with the left and soft libertarian arguments). To my mind, this points in the direction of priority in content. Setting aside notions of historical priority, why would conformity to background principles facilitate conformity to foreground principles' expression of genuine freedom and fairness if not because the values expressed by each type of principle were conceptually connected? And, in that case, why view the priority of one type of principle as priority in conflict, which suggests that the value expressed by the defeated principle loses out to that expressed by the victor?

"See e.g. Joshua Cohen and Charles Sabel, “Extra Rempublicam Nulla Justitia?”, Philosophy \& Public Affairs 34, no. 2 (2006).

${ }^{*}$ Assuming that the social ideal is not in tension with the values expressed by the Lockean foreground principles, in which case it cannot provide the basis of a background justice argument at all. (See section 2 above.)

"See "Cooperation, Pervasive Impact, and Coercion", 333-4.

${ }^{45}$ See “The Global Order", especially 244, 254-5.

${ }^{4}$ This is not a criticism of Rawls. The background justice argument is not intended by him to justify any conclusions about the scope of background principles. 